\title{
Erythrokeratoderma variabilis progressiva
}

INSERM

\section{Source}

INSERM. (1999). Orphanet: an online rare disease and orphan drug data base.

Erythrokeratoderma variabilis progressiva. ORPHA:308166

Erythrokeratoderma variabilis progressiva (EKVP) is a type of erythrokeratoderma

characterized by the association of hyperkeratosis and erythema in persistent, although sometimes variable, circumscribed lesions. Progressive symmetric erythrokeratoderma (PSEK) and erythrokeratoderma variabilis (EKV) are probably no longer two distinctive diseases but rather the two clinical manifestations of a same disease, now known as EKVP. 